\title{
Expert consensus on nebulization therapy in pre-hospital and in-hospital emergency care
}

Chinese College of Emergency Physicians (CCEP), Emergency Committee of PLA, Beijing Society for Emergency Medicine, Chinese Emergency Medicine

Correspondence to: Xiaodong Zhao. Department of Emergency, First Affiliated Hospital of Chinese PLA General Hospital, Beijing 100048, China. Email: ZXD63715@126.com; Xuezhong Yu. Department of Emergency, Peking Union Medical College Hospital, Beijing 100032, China. Email: yxz@pumch.cn.

Submitted Jul 11, 2019. Accepted for publication Sep 06, 2019.

doi: $10.21037 / \mathrm{atm} .2019 .09 .44$

View this article at: http://dx.doi.org/10.21037/atm.2019.09.44

\section{Introduction}

Emergency patients typically present with sudden onset and complex symptoms, the cause is often unclear, and many of the patients are elderly, children, or in critical conditions $(1,2)$. Respiratory diseases and symptoms constitute a large part of the cases (1,3-6).

Nebulization therapy has a unique and vital position in the treatment of respiratory diseases. It has several advantages, such as the rapid onset of action, proved efficacy, good safety profile, and is widely used in many respiratory diseases. Nebulization therapy is suitable for most patients, including children, elderly, patients on mechanical ventilation, with a cognitive disorder or are unable to use other inhalation devices $(7,8)$. It plays an essential role in emergency care with conditions including acute asthma attacks, acute exacerbation of the chronic obstructive pulmonary disease, acute laryngeal obstruction, acute respiratory infection, respiratory distress syndrome, severe pneumonia, acute respiratory failure, aspirationinduced lung injury, and endotracheal intubation. Nebulization therapy fulfills the needs of pre-hospital and in-hospital emergency care, which calls for rapid, effective, safe, easy to use, and widely applicable remedies, hence deserving further exploration and promotion.

However, there are no standards for the application of nebulization therapy in pre-hospital and in-hospital emergency care in China, and the utilization rate is far from clinically needs (9). In order to answer the call for national
"Guidance on establishing a platform for pre-hospital and in-hospital emergency care", and to further promote nebulization therapy use and facilitate the development of an integrated platform for pre-hospital and in-hospital emergency care, the Emergency Medicine Branch of Chinese Medical Doctor Association, Emergency Medical Specialized Committee of PLA, Beijing Emergency Medicine Association and the Chinese Emergency Medicine Consortium conducted multiple rounds of consultation and discussion with experts in the field and developed this consensus statement. We hope to provide theoretical and practical guidance on nebulization use in emergency medicine, thus improving treatment and eventually benefiting more patients.

\section{Basic principles and SOPs for nebulization therapy in pre-hospital and in-hospital emergency care}

Nebulization therapy aims to deliver a therapeutic dosage of a drug by inhalation of the drug-aerosol, which is generated with a drug solution or suspension by a nebulizer, through the mouth, nose or artificial airway (including endotracheal and tracheotomy tubes) into airways and lungs. Nebulization therapy can also serve as a support and supplement to systemic therapy. It has a relatively lower requirement for patient's coordination and can be used to deliver a large dosage of drugs in combination, and in 
Table 1 Comparison of characteristics of nebulizers

\begin{tabular}{lll}
\hline Nebulizer type & Advantages & Disadvantages \\
\hline Jet nebulizer & $\begin{array}{l}\text { Simple structure, durable, widely } \\
\text { used in clinical applications }\end{array}$ & $\begin{array}{l}\text { May ponerate noise, must be driven by compressed gas or power supply (mostly } \\
\text { AC power }\end{array}$ \\
$\begin{array}{ll}\text { Ultrasonic nebulizer } \\
\text { Able to generate large quantity } \\
\text { of aerosol, no noise }\end{array}$ & $\begin{array}{l}\text { Need power supply (mostly an AC power source), prone to drug degeneration; } \\
\text { May cause inhalation of excessive water and decrease oxygen concentration } \\
\text { when provided with too much aerosol; More water that drug in aerosol if the drug } \\
\text { is in suspension form (the energy needed to turn water into an aerosol is lower } \\
\text { than that needed to turn drug suspension into aerosol) }\end{array}$ \\
$\begin{array}{ll}\text { Vibrating mesh } \\
\text { nebulizer }\end{array}$ & $\begin{array}{l}\text { No noise, compact, light, } \\
\text { battery-driven optional }\end{array}$ & Need AC power or battery, durability not fully confirmed, fewer devices available \\
\hline
\end{tabular}

intermittent or continuous treatment with concomitant oxygen supply, making it a flexible and convenient choice for pre-hospital and in-hospital emergency care.

\section{Indications for nebulization therapy in pre-hospital and in-bospital emergency care}

Nebulization therapy can be used to treat respiratory diseases or respiratory-related symptoms in emergency care. It can also be used as a prophylactic measure of airway management in other diseases. No absolute contraindications are noted.

The goal of nebulization therapy can be briefly summarized as "SHAPE":

* S (Relief airway Spasm): to relieve bronchospasm, coughing and wheezing;

* H (Humidify): to humidify airway;

* An (Anti-inflammation): to achieve an antiinflammatory effect;

* P (Prevent): to prevent respiratory complications such as airway inflammation, obstruction, atelectasis, infection, and asphyxia;

* E (Expectorant): promote expectoration.

\section{Basic principles for nebulization therapy in pre-hospital and in-hospital emergency care}

Although it is an effective treatment measure, nebulization therapy can only be conducted when a patient's safety Is ensured first. If a patient is in state of, or shows the sign of unconsciousness or coma, or stupor with superficial breathing, no aortic pulsation, no breathing or abnormal breathing, cyanosis, poor or lack of pain sensation reflex, lack of vomiting reflex or cough reflex, it is essential to stabilize vital signs first and perform advanced life support measures such as cardiopulmonary resuscitation, endotracheal intubation and mechanical ventilation as needed. After the vital signs are stabilized, nebulization therapy may be considered. However, in cases when it is deemed necessary, nebulization therapy may be administered concomitantly with the stabilization of the vital signs. Also, the efficacy and adverse reactions should be evaluated and treated promptly during and after the treatment, and the treatment protocol should be adjusted accordingly.

\section{Common nebulizers and drugs (also see Tables S1,S2)}

\section{Common nebulizers}

The nebulizers commonly used in current clinical practice are mainly divided into three types based on the mechanism of aerosol generation: jet nebulizer, ultrasonic nebulizer, and vibrating mesh nebulizer. The characteristics are shown in Table 1.

Jet nebulizers are the most widely used nebulizing devices in clinical practice. It does not affect drug stability and concentration and is, therefore, suitable to be used in pre-hospital and in-hospital emergency care, such as in ambulance and emergency rescue room, infusion room, intensive care unit and emergency ward.

A jet nebulizer is mainly composed of compressed gas source and nebulizer. The compressed gas source can be either bottled compressed gas (such as high-pressure oxygen or compressed air) or power-driven compression pump. For hypoxic patients with dyspnea and wheezing, the use of oxygen-driven nebulization is recommended to improve 
Table 2 Comparison of pharmacological properties of three ICSs

\begin{tabular}{lccc}
\hline Pharmacological properties & Beclomethasone dipropionate/17-BMP & Budesonide & Fluticasone propionate \\
\hline Glucocorticoid receptor affinity & $140 / 1,440$ & 850 & 1,540 \\
Time for effect onset & Within 3 days & $3 \mathrm{~h}$ & $12 \mathrm{~h}$ \\
Hydrophilicity $(\mu \mathrm{g} / \mathrm{mL})$ & $0.1 / 10$ & 3.6 & 0.04 \\
Lipophilicity $($ log $\mathrm{P})$ & $4.9 / 4.3$ & Length & 4.5 \\
Pulmonary retention time & Short & 88 & Intermediate \\
Plasma protein binding rate $(\%)$ & 87 & 84 & 90 \\
System clearance rate $(\mathrm{L} / \mathrm{h})$ & $150 / 120$ & 2.8 & 69 \\
Elimination half-life $(\mathrm{h})$ & $0.5 / 2.7$ & Low & High \\
Adrenal cortical inhibition & Low & & 7.8 \\
\hline
\end{tabular}

oxygenation and prevent the decline of the arterial partial pressure of oxygen $\left(\mathrm{PaO}_{2}\right)$ due to changes in ventilation/ perfusion (V/Q) ratio after inhalation of $\beta 2$ agonist. For patients prone to $\mathrm{CO}_{2}$ retention (such as chronic obstructive pulmonary disease with respiratory failure), the use of compressed air driven nebulizer is recommended. In such patients, the respiratory excitation is mainly stimulated by hypoxia. The improvement in hypoxia leads to a decline in low oxygen stimulation, thereby resulting in an inhibition of spontaneous breathing and aggravation of $\mathrm{CO}_{2}$ retention.

\section{Commonly used drugs and precautions}

Currently, the commonly used drugs for nebulization in China include inhaled corticosteroids (ICS), bronchodilators, and mucolytic agents. No other commercially available drugs are indicated for nebulization. It is not recommended to use drugs without indication for nebulization. The ideal drug used in emergency care should have a rapid onset of action, clear dose-effect relationship, and precise therapeutic target. The following drugs are recommended in this consensus for emergency use.

\section{ICS}

ICS remains to be the most potent topical airway antiinflammatory drug. It exerts the effects by influencing a series of cells and molecules in inflammatory reactions. ICS has the following characteristics: (I) it is directly delivered to airways and lungs, showing more significant improvement for respiratory symptoms and lung function within the first 1 and 2 hours following administration than systemic glucocorticoids (10); (II) it can effectively control airway inflammation, inhibit mucosal hypersecretion, and reduce mortality (11); (III) administered with a low dosage, ICS has a good safety profile and lower incidence rate of adverse events than systemic glucocorticoids (12). Spontaneous remission of common adverse events such as hoarseness and sore throat is generally to be expected after drug withdrawal.

Budesonide has the most rapid onset of action among the ICS and is currently the most commonly used ICS in emergency care. Beclomethasone dipropionate (BDP) and fluticasone propionate (FP) are also used (10,13-16). A comparison of the three ICSs is shown in Table 2.

ICS is contraindicated in patients allergic to any glucocorticoid. In case of any misuse, intravenous injection or infusion of epinephrine should be administered immediately, with the inhalation of $100 \%$ oxygen. If necessary, tracheal intubation and cardiopulmonary resuscitation should be performed.

\section{Bronchodilators}

Bronchodilators are categorized into selective $\beta 2$ receptor agonist and cholinergic receptor antagonist. They can also be divided into short-acting and long-acting types depending on the onset and duration of effect. Currently, all domestic bronchodilators inhalers are short-acting. (I) Short-acting beta2 agonists (SABAs), with synergistic effects with ICS, are the main drugs for relieving bronchospasm and treating acute asthma. E.g., salbutamol and terbutaline; (II) short-acting muscarinic antagonists (SAMAs), which acts mainly on large airway rather than 
Table 3 Other drugs proved by FDA for nebulization (https://www. fda.gov/)

\begin{tabular}{|c|c|}
\hline Drug & Indication \\
\hline FLUNISOLIDE & Asthma \\
\hline CICLESONIDE & $\begin{array}{l}\text { Asthma } \\
\text { (NOT indicated for the relief of acute } \\
\text { bronchospasm) }\end{array}$ \\
\hline $\begin{array}{l}\text { MOMETASONE } \\
\text { FUROATE }\end{array}$ & $\begin{array}{l}\text { Asthma } \\
\text { (NOT indicated for the relief of acute } \\
\text { bronchospasm) }\end{array}$ \\
\hline $\begin{array}{l}\text { FORMOTEROL } \\
\text { FUMARATE; } \\
\text { MOMETASONE } \\
\text { FUROATE }\end{array}$ & $\begin{array}{l}\text { For the twice-daily treatment } \\
\text { of asthma in patients } 12 \text { years of age } \\
\text { and older (NOT indicated for the relief } \\
\text { of acute bronchospasm) }\end{array}$ \\
\hline TOBRAMYCIN & $\begin{array}{l}\text { To treat people with a certain inherited } \\
\text { condition (cystic fibrosis) who have } \\
\text { persistent lung infection with a certain } \\
\text { bacteria (Pseudomonas aeruginosa). }\end{array}$ \\
\hline CROMOLYN SODIUM & $\begin{array}{l}\text { Adjunct in the management of patients } \\
\text { with asthma } \\
\text { Prevention of bronchospasm }\end{array}$ \\
\hline TREPROSTINIL & Pulmonary arterial hypertension \\
\hline ILOPROST & Pulmonary arterial hypertension \\
\hline AZTREONAM & $\begin{array}{l}\text { To improve respiratory symptoms in } \\
\text { cystic fibrosis (CF) patients } \\
\text { With Pseudomonas aeruginosa }\end{array}$ \\
\hline $\begin{array}{l}\text { PENTAMIDINE } \\
\text { ISETHIONATE }\end{array}$ & $\begin{array}{l}\text { To prevent a serious lung infection } \\
\text { (Pneumocystis pneumonia-PCP) in } \\
\text { people with acquired immunodeficiency } \\
\text { syndrome (AIDS) }\end{array}$ \\
\hline $\begin{array}{l}\text { METHACHOLINE } \\
\text { CHLORIDE }\end{array}$ & $\begin{array}{l}\text { For the diagnosis of bronchial airway } \\
\text { hyperreactivity in subjects who do not } \\
\text { have clinically apparent asthma }\end{array}$ \\
\hline
\end{tabular}

the small airway, has a weaker bronchodilating effect, a slower onset but longer duration of effect, as compared to SABA (17). e.g., ipratropium bromide; (III) compound Ipratropium Bromide Solution for Inhalation, containing $0.5 \mathrm{mg}$ of ipratropium bromide and $2.5 \mathrm{mg}$ of salbutamol in each $2.5 \mathrm{~mL}$ dose. Caution must be exercised not to blend with other drugs in the same nebulizer. SABA is the preferred choice as bronchodilators; if necessary, use in combination with SAMA aerosol inhalation. Patients with tachycardia or concomitant cardiovascular disease should choose terbutaline based on its higher selectivity for the $\beta 2$ receptor than that of salbutamol, therefore a lower risk of cardiovascular adverse events. Patients who experience palpitation during nebulization therapy should discontinue SABA and keep monitored until the symptoms disappear before continuing with nebulization therapy. If symptoms persist or deteriorated, selective $\beta 1$ blockers can be administered also.

\section{Mucolytic agent}

$\mathrm{N}$-acetylcysteine is a classic mucolytic agent. The unique hydrosulfuryl(-SH) group breaks the disulfide bond (-SS) between mucin molecular complexes, thereby reducing the viscosity of sputum (18). Also, it can promote ciliary movement, improve mucociliary clearance capacity (19) and increase the secretion and activity of pulmonary surfactant, thus promote mucus discharge. Furthermore, $\mathrm{N}$-acetylcysteine also has a strong antioxidant effect, which can reduce oxidative stress damage in respiratory diseases (20). Recent studies have indicated that $\mathrm{N}$-acetylcysteine can also impair and inhibit the formation of bacterial biological membrane. When used alone or in combination with antibiotics, it can inhibit respiratory infections (21).

Currently, $\mathrm{N}$-acetylcysteine is the only mucolytic agent in China with nebulizer formulation. Upon nebulization, it can quickly reach the lung. It must be noted that although intravenous preparation of ambroxol is frequently used for nebulization therapy in clinical practice, it is not labeled for that. Further clinical studies are needed to validate the dosage, concentration, efficacy, and safety for it to be used for nebulization therapy. Case reports are suggesting that asthma attacks may be induced, which may be associated with the preservatives in the preparations. Therefore, the use of ambroxol intravenous preparation for nebulization is not recommended.

\section{Other drugs}

Some drugs (such as tobramycin, sodium cromoglycate, treprostinil, and aztreonam), are currently not commercially available with nebulizer formulation in China, but their efficacy has been clinically validated. Other FDA-approved nebulization drugs are listed in Table 3.

\section{Precautions in choosing nebulization drugs}

(I) Patient with a history of allergies. Avoid using the drug if there was a previous history of an allergic reaction to it (22); 
(II) if the inhalation of foreign bodies caused signs and symptoms, no routine nebulization therapy is necessary;

(III) concomitant treatment contraindication: there were rare cases when concomitant administration of salbutamol and ipratropium bromide aerosol were used, patients experienced closed-angle glaucoma. Special caution must be taken when concomitantly use above-mentioned aerosolized drugs and similar agents;

(IV) patients with serious cardiovascular diseases (such as ischemic heart disease, tachyarrhythmia or severe heart failure), with a heart rate or pulse $>120$ beats $/ \mathrm{min}$ or with uncontrolled thyrotoxicosis are not recommended to use SABA (refer to the package insert of Terbutaline sulfate nebulizing solution and Salbutamol sulfate inhalation solution);

contraindications in patients with underlying conditions; for example, children, pregnant women, elderly, long-term bedridden patients, and patients with various complications. Special attention should be paid to the previous history of medications and contraindications; (VI) other treatment measures should also be used.

\section{Drug and equipment requirements for nebulization therapy in pre-hospital and in-hospital emergency care}

When allocating aerosol inhalation devices and drugs, the seamless connection between pre-hospital care and inhospital care should be considered. The consistency at each link should be highlighted. Below is the list of the recommended equipment and drugs. Adjust according to actual visits and patient turnover to ensure sufficient supply.

\section{List of aerosolized drugs:}

* ICSs: recommend Budesonide suspension for inhalation $1 \mathrm{mg}(2 \mathrm{~mL})$;

* Short-acting bronchodilator (short-acting beta agonist, SABA): recommend Terbutaline sulfate solution for nebulization $5 \mathrm{mg}(2 \mathrm{~mL})$ or Salbutamol sulfate inhalation solution $5 \mathrm{mg}(2.5 \mathrm{~mL})$;

* Mucolytic agent: recommend $\mathrm{N}$-acetylcysteine solution for inhalation $0.3 \mathrm{~g}(3 \mathrm{~mL})$.

\section{List of equipment and supplies: \\ * Compressed air nebulizer and electrical outlet, oxygen}

cylinder;

* Mouthpiece/facial mask;

* Nebulizing cup;

* Connecting cognitive disorder;

* The use of vibrating mesh nebulizer does not require nebulizing cup and connecting cognitive disorders. The aforementioned nebulized drugs and equipment supplies should be organized and placed for easy access.

\section{Factors affecting nebulization efficiency}

The factors affecting the nebulization efficiency can be divided into three categories, "device, drug, and patient", i.e., the inherent efficiency of the nebulizing device, the inherent characteristics of the nebulized drug, and the patient (8).

\section{Nebulizer}

The nebulizer is the device that generates aerosol. The primary factors affecting the nebulization efficiency are as follows:

(I) output efficiency of effective nebulized particles; effective nebulized particles refer to nebulized particles with therapeutic values, i.e., that can be deposited in the airway and lung, preferably with a diameter of 3.0-5.0 $\mathrm{mm}$; the particles with a diameter of 5-10 $\mu \mathrm{m}$ are mainly deposited in the large airways and oropharynx. The particles with a diameter of 1-5 $\mu \mathrm{m}$ are mainly deposited in the small airways. About $40-48 \%$ of the particles with a diameter of fewer than $3 \mu \mathrm{m}$ are deposited in the alveoli, and the particles with a diameter of fewer than $0.5 \mu \mathrm{m}$ are excreted along with exhalation $(23,24)$;

(II) the output volume per time unit: higher output is correlated with more inhalation and high dose and potentially stronger therapeutic efficacy. Meanwhile, higher dose within a short time can also increase adverse reaction. A comprehensive assessment should be made.

Differential nebulizing devices are based on different mechanisms:

(I) Jet nebulizer. The diameter of the generated aerosol particles and the amount of output depend on the pressure and flow rate of the compressed air, as well as on the structural parameters of internal resistance based on brand and version. The pressure and flow rate of the compressed gas 
are directly proportional to the amount of output and inversely proportional to the diameter of the aerosol particles. Higher the pressure and higher the flow rate, the smaller is the diameter of the aerosol particles produced by the jet nebulizer and the larger the amount of aerosol output;

(II) Ultrasonic Nebulizer. The diameter of the released particles is negatively correlated with the ultrasonic frequency. The higher the frequency, the smaller the particle. The amount of released aerosol is positively correlated with the ultrasonic amplitude (power). The greater the intensity, the greater the amount of released mist. In general, ultrasonic nebulizer generates a higher amount of aerosol than a jet nebulizer;

(III) Vibrating mesh nebulizer. The size of produced particles depends on the diameter of the mesh. The device reduces the effect of heat generated by ultrasonic liquid vibration, exerts less effect on drug integrity. It is considered the most effective nebulizer so far.

\section{Drug}

Size and shape of the drug particle can also affect the proportion of effective drug aerosol generated, using ICS as an example. Budesonide suspension is shown as small round particles of a diameter of 2.0-3.0 $\mu \mathrm{m}$ under an electron microscope, while the drug particles of beclomethasone propionate suspension are needlelike particles about $10.0 \mu \mathrm{m}$ in length. In vitro studies have shown that the output of effective aerosol was much higher for budesonide than that for beclomethasone using different brands of nebulizers (25).

\section{Patient}

The patient's cognition and ability to coordinate, breathing pattern, and general disease status can affect the nebulization efficiency.

(I) Cognition and ability to coordinate. The patient's cognitive status and the ability to cooperate also determines whether the nebulizer can be effectively used. Regardless of the type of the nebulizer used, as long as it is used correctly, a similar clinical effect can be achieved.

(II) Breathing pattern. The breathing parameters that affect aerosol deposition include inspiratory flow, airflow pattern, breathing frequency, inspiratory volume, inspiration/expiration ratio, and maintenance of the inspiratory state. Slow and deep breathing facilitates the deposition of aerosol particles in the lower respiratory tract and alveoli. The intrapulmonary deposition is less when the breathing rate is fast, and the inspiratory volume is small. An abnormal fast inspiratory flow rate is prone to result in local turbulence, causing aerosol to deposit on the large airway due to the collision, resulting in a significant decline in an intrapulmonary deposition. When the inspiratory capacity maintains constant, with an increase in tidal volume and the extension in inspiratory time, deep and slow breathing is more beneficial for aerosol deposition.

(III) General disease status. Status of patients' respiratory system can affect the delivery of aerosols in the respiratory tract. Inflammation, swelling, and spasm of the tracheal mucosa and retention of secretions can result in increased airway resistance and uneven distribution of inhaled aerosols; Drug concentration in the stenotic site may increase, and the drug deposition at the distal end of the obstruction site may be low, compromising the clinical efficacy. Therefore, sputum and atelectasis should be eliminated as much as possible before nebulization therapy to facilitate aerosol deposition in the lower respiratory tract and lung.

\section{General protocol and precautions for nebulization therapy}

\section{General protocol for nebulization therapy}

(I) Patient assessment: evaluate whether a patient is suitable for nebulization therapy and choose the appropriate nebulizer. Patients with clear consciousness and high cooperativeness should wear a mouthpiece. Facial masks are used in patients with a cognitive disorder, severe illness, or poor coordination (22).

(II) Keep the airway open: check for any foreign body or secretions in the respiratory tract. Excessive sputum should be removed by coughing or by suction.

(III) Patient education: briefly inform about the treatment purpose and procedures before nebulization. Inform patients to take slow and deep breaths, inhale 

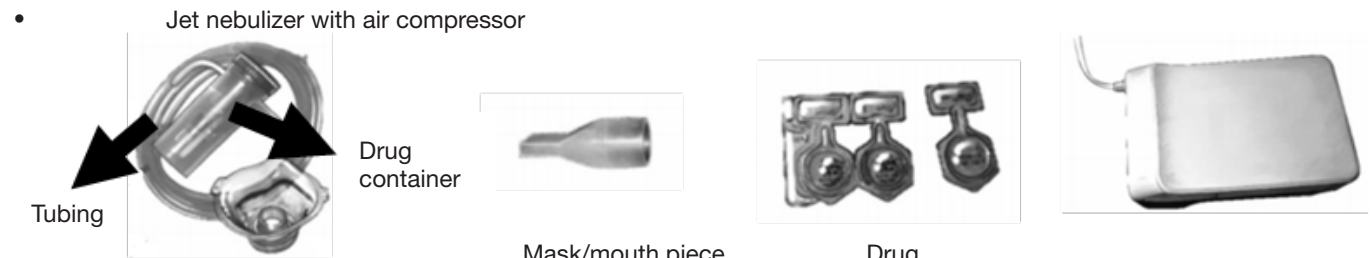

Mask/mouth piece

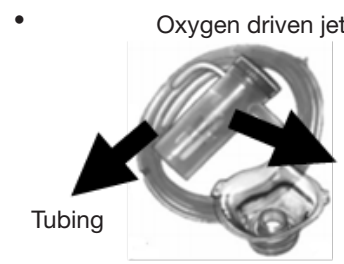

Drug
container

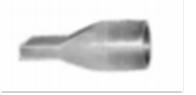

Mask/mouth piece

Drug

•

Mesh nebulizer

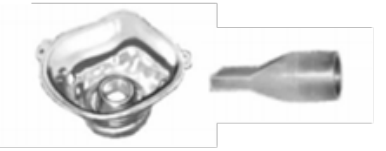

Mask/mouth piece

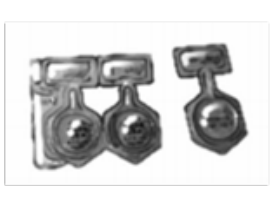

Drug

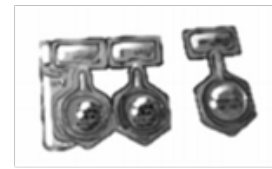

Drug

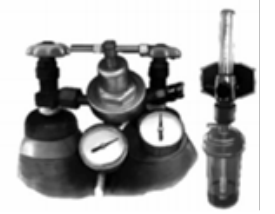

High pressor oxygen tank

Figure 1 Item and drug preparation for nebulization therapy.

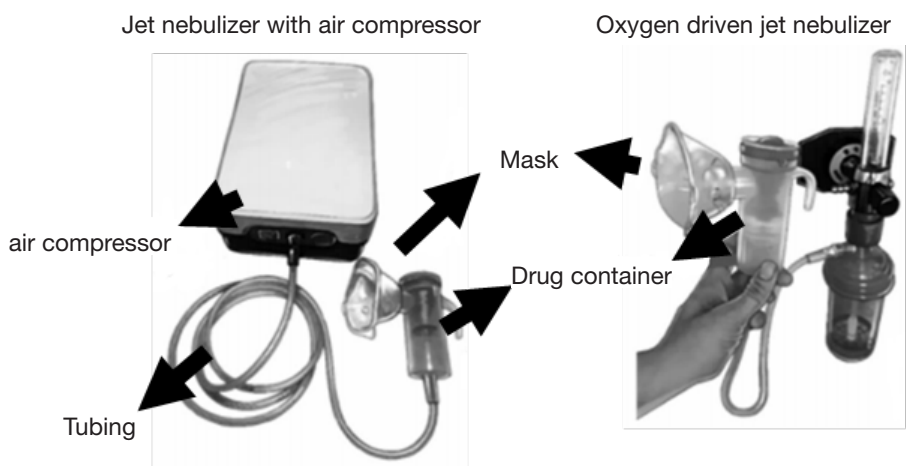

Mesh nebulizer

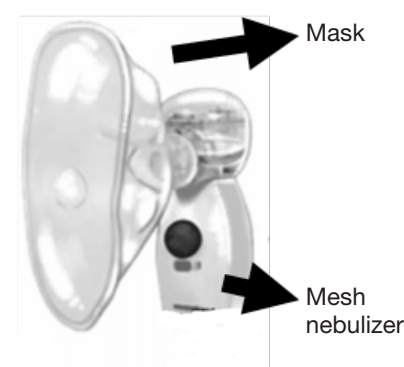

Figure 2 Connecting tubing and nebulizer.

through the mouth, and exhale the nasal cavity (22).

(IV) Appropriate body position: conscious patients are recommended to take a semi-recumbent or sitting position; patients with the cognitive disorder or weak cough are recommended to take the recumbent position, with the head of the bedstead raised by $30^{\circ}$, and treatment towel is placed under the patient's jaw (22).

(V) Item and drug preparation: as shown in Figure 1.

(VI) Tubing connection: connect the compressed air nebulizer or oxygen cylinder, and connect the tubing, nebulizer, mouthpiece, or mask; install the mask or mouthpiece on the vibrating mesh nebulizer (see Figure 2). Combine the mechanical ventilation with nebulization treatment, to determine whether the ventilator has the nebulization function, and adjust the parameters related to ventilator performance.

(VII) Use of mouthpiece or mask: guide and assist the patient to effectively harbor the mouthpiece in the mouth or wear a face mask. Advice patient to inhale the nebulized drug. 
(VIII) Initiation of nebulization therapy: for patients using compressed air nebulizer or vibrating mesh nebulizer initiate the nebulization. For patients using an oxygen-driven nebulizer, turn on the oxygen, adjust the oxygen flow from low to high (usually 6-8 L/min), and observe the output of nebulized liquid (22). The aerosol inhalation lasts for about 15 to $20 \mathrm{~min}$. Keep a close observation, monitor adverse reactions, and take timely measurements. Efficacy should be assessed meanwhile.

(IX) End of aerosol inhalation treatment: guide and assist the patient in rinsing the mouth or applying oral care. Pat on the back to force out sputum. Those who wear masks should also wash faces. Record efficacy and adverse effects. Evaluate and adjust therapeutic regimens as appropriate.

\section{Operational precautions for nebulization treatment}

(I) The nebulizing cup, breathing cognitive disorder, and nebulizing mask should be personal. The use of disposable devices is recommended.

(II) Although nebulization therapy is less demanding on inhalation technique and coordination $(23,26)$, it is still recommended that patients be guided to practice correct breathing pattern (with mouthpiece engaged between lips, slowly inhale, hold the breath for 2-3 seconds after a deep inhalation, slowly exhale through nasal cavity), to achieve better therapeutic results.

(III) Oily facial cream should be removed before treatment if the mask is needed. Keep liquid or aerosol away from eyes to reduce irritation.

(IV) Gargling and oral care after treatment can significantly reduce the incidence of adverse reactions such as hoarseness, sore throat, and candida infection (27);

(V) The membrane at the expiratory end of the ventilator should be cleaned, tested, and replaced regularly to avoid damage to the internal precision components of the ventilator.

\section{Efficacy evaluation of nebulization therapy}

The efficacy evaluation should be carried out at $0,5,10$, 30 minutes from the start of nebulization (27):

* Improvement: (I) elimination or improvement of original respiratory symptoms. No newly-emerging respiratory symptoms; (II) improvement of abnormal signs; for example, reduced wheezing in pulmonary auscultation, absence of newly-emerging abnormal signs; (III) respiratory rate, heart rate, or pulse return to normal as indicated by the monitoring system. $\mathrm{SpO}_{2}$ rebounds.

* No change: (I) no change in the original respiratory symptoms. No new abnormal physical signs; (II) no change in original abnormal signs, no new abnormal physical signs; (III) no significant improvement in respiratory rate, $\mathrm{SpO}_{2}$, heart rate, or pulse as indicated by the monitoring system. Alternatively, no consistent trend of change.

- Aggravation: (I) exacerbation of original respiratory symptoms. The occurrence of new abnormal physical signs; (II) exacerbation of original abnormal signs. The occurrence of new abnormal physical signs; (III) the appearance of abnormal respiratory rate, $\mathrm{SpO}_{2}$, heart rate, or pulse as indicated by the monitoring system.

\section{Monitoring and management of adverse reactions of nebulization therapy}

Adverse reactions should be closely monitored during the aerosol inhalation treatment. Cause of adverse events should be immediately evaluated, and timely actions are taken. Common adverse reaction symptoms, possible causes, and recommended clinical management are listed in Table 4.

\section{Application of aerosol inhalation in pre-hospital care}

\section{Indications of nebulization treatment in pre-hospital first aid}

If symptoms or signs of airway hyperreactivity is indicated, the nebulization treatment is recommended:

(I) Patients with respiratory symptoms such as dyspnea, coughing, expectoration, or chest tightness.

(II) Abnormal physical signs such as cyanosis of lips, shortness of breath, and three concave sign or dry or moist rales (especially wheezing sounds) as shown in the pulmonary auscultation. 
Table 4 Common adverse reactions and treatment methods in nebulization treatment

\begin{tabular}{|c|c|c|}
\hline $\begin{array}{l}\text { Adverse reaction } \\
\text { symptoms }\end{array}$ & Possible causes & Recommended clinical management \\
\hline Allergic reaction & Allergy to aerosolized drug or drug ingredients & $\begin{array}{l}\text { Detailed Inquiry about the patient's allergic history; } \\
\text { close monitor of the patient's reactions; intravenous } \\
\text { administration of adrenaline and other related treatment as } \\
\text { appropriate }\end{array}$ \\
\hline $\begin{array}{l}\text { Aggravation in } \\
\text { coughing and } \\
\text { dyspnea. }\end{array}$ & $\begin{array}{l}\text { Change of ventilation/perfusion ratio and a decline } \\
\text { in the arterial oxygen partial pressure following } \\
\text { nebulization treatment with the } \beta 2 \text { receptor agonist } \\
\text { (especially salbutamol) }\end{array}$ & $\begin{array}{l}\text { Use oxygen-driven aerosol inhalation, or reduce or } \\
\text { temporary discontinue } \beta 2 \text { receptor agonist treatment. } \\
\text { Apply oxygen inhalation }\end{array}$ \\
\hline $\begin{array}{l}\text { Severe cough, severe } \\
\text { hypoxia }\end{array}$ & $\begin{array}{l}\text { Mucus plug or massive dilution of sputum and retention } \\
\text { in the airway }\end{array}$ & $\begin{array}{l}\text { Patients with massive and thick sputum should be assisted } \\
\text { with sputum suction and patting on the back. Oxygen } \\
\text { inhalation can be performed if necessary }\end{array}$ \\
\hline $\begin{array}{l}\text { Tachycardia or } \\
\text { arrhythmia }\end{array}$ & $\begin{array}{l}\text { More common in an overdose of } \beta 2 \text { receptor agonists } \\
\text { inhalation (especially salbutamol) }\end{array}$ & Reduce or temporarily discontinue $\beta 2$ receptor agonists \\
\hline $\begin{array}{l}\text { Dizziness, hand } \\
\text { numbness }\end{array}$ & $\begin{array}{l}\text { More common in young and middle-aged patients or } \\
\text { first-time receiver for nebulization therapy. Induced } \\
\text { by the hyperventilation resulting from nervousness or } \\
\text { excessively frequent inhalation }\end{array}$ & $\begin{array}{l}\text { Advice patients to relax and breath normally when receiving } \\
\text { nebulization treatment }\end{array}$ \\
\hline
\end{tabular}

\section{Recommendation in the nebulization treatment regimen for pre-hospital emergency care}

A comprehensive assessment will be made based on the patient's conditions. The use of ICS [e.g., budesonide $2 \mathrm{mg}(4 \mathrm{~mL})$ ] +/- SABA [e.g., terbutaline $5 \mathrm{mg}(2 \mathrm{~mL})$ or salbutamol $5 \mathrm{mg}(2.5 \mathrm{~mL})$ ] is routinely recommended.

A compressed air-driven spray nebulizer is generally employed. In patients with obvious hypoxemia or hypoxia, an oxygen-driven jet nebulizer is recommended if possible. During the oxygen-driven nebulization, no additional oxygen inhalation is required (27).

\section{Continued nebulization therapy from home care to pre- hospital and in-hospital emergency care}

For patients who have home care nebulization system, in case of emergency, before the ambulance arrival, nebulization treatment should be performed at home based on the patient's conditions and be continued when transferred to the ambulance.

The recommended duration for nebulization treatment is 15 minutes, during which the patient's conditions are closely monitored.

If the nebulization treatment has not been completed when arriving hospital, for patients using a portable mesh nebulizer or connected with a portable oxygen cylinder on the ambulance, the nebulization treatment should be continued; For patients using a compressed air nebulizer, pause the treatment first, bring the nebulizing cup and continue the nebulization treatment when arriving hospital.

\section{Procedures of nebulization treatment for pre-bospital first aid}

Emergency medical staff should evaluate patient's vital signs and conscious state first and follow the procedure of nebulization therapy for pre-hospital first aid (Figure 3). 


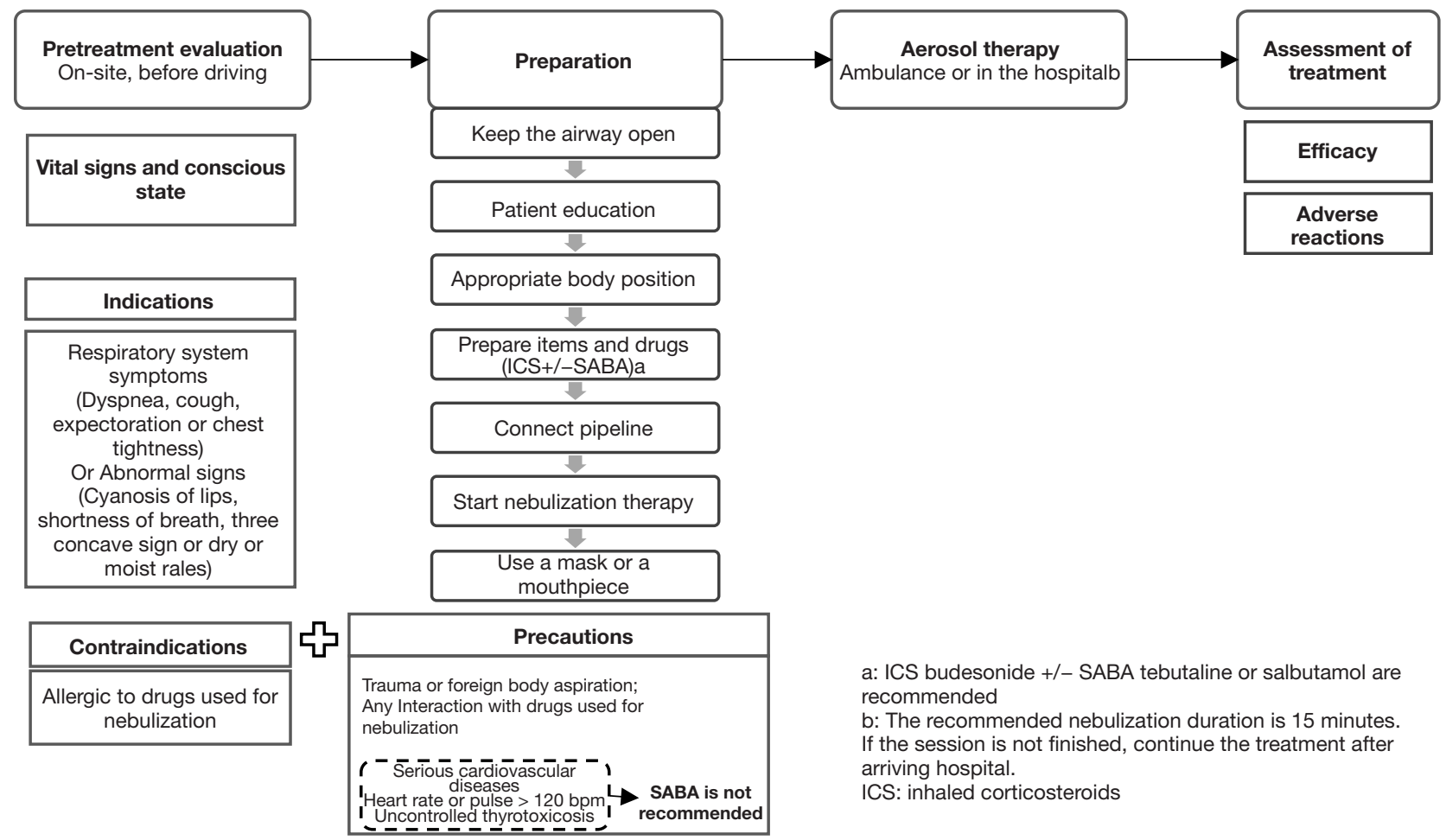

Figure 3 Procedures of nebulization therapy for pre-hospital first aid.

Table 5 Assessment criteria for the severity of an acute asthma attack (27)

\begin{tabular}{|c|c|c|c|c|}
\hline Clinical characteristics & Mild & Moderate & Severe & Critical \\
\hline speech pattern & Sentences & Phrases & Word & Unable to talk \\
\hline Mental status & occasional anxiety, still quiet & $\begin{array}{l}\text { Frequent anxiety or } \\
\text { irritability }\end{array}$ & $\begin{array}{l}\text { Constant anxiety and } \\
\text { irritability }\end{array}$ & Drowsy or confused \\
\hline Wheezing rale & $\begin{array}{l}\text { Scattered, end-stage of } \\
\text { breathing }\end{array}$ & Loud, diffuse & Loud, diffuse & $\begin{array}{l}\text { Weakened or even } \\
\text { absent }\end{array}$ \\
\hline
\end{tabular}

\section{Application of nebulization therapy in the emergency department}

\section{Acute attack of asthma}

\section{Assessment and treatment}

It is essential that patients are moved away from the environment and allergens that may trigger an acute asthma attack. Patients should be assessed and graded (Table 5) and given corresponding treatments (Figure 4).

\section{Precautions}

(I) The treatment purpose of an acute asthma attack is to relieve the patient's respiratory symptoms, mitigate bronchospasm, improve hypoxia, restore 


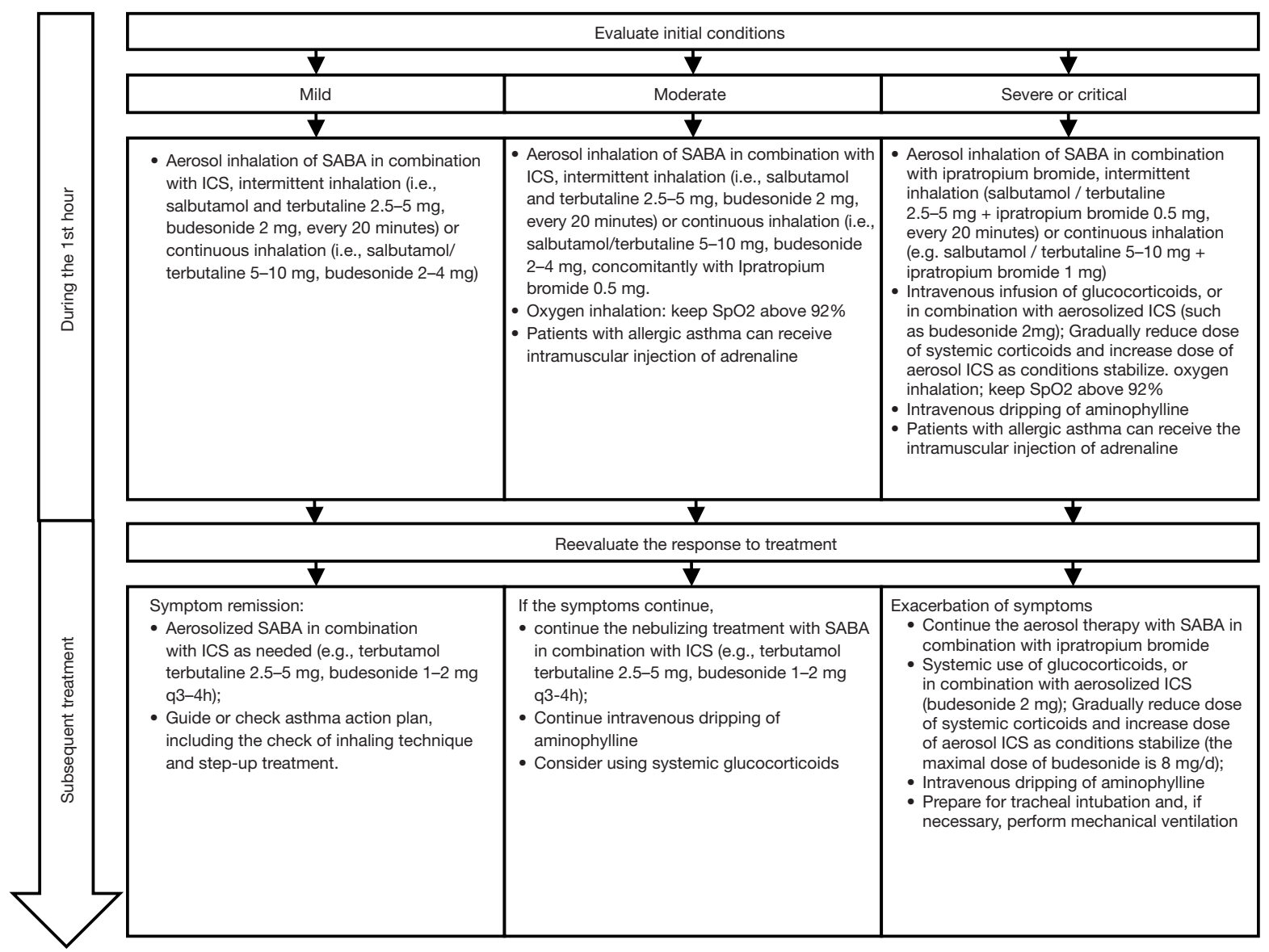

Figure 4 Procedures for the management of acute asthma attack (27).

lung function, prevent further deterioration or recurrence, and prevent complications (27).

(II) In general, if symptoms fluctuate or mild to moderate acute attacks occur during asthma control, self-management can be performed according to the "Asthma Action Plan", i.e., to repeat SABA inhalation (aerosol inhalation of salbutamol/terbutaline, initially intermittently (every 20 minutes) or continuously, followed by intermittent administration(every 4 hours), or use pMDI inhalation), or use lowdose ICS/formoterol combination (no more than 8-12 inhalations per day in total), can use SAMA concomitantly, with ICS dose increased to 2-4 times of the usual dose, up to $1,600 \mu \mathrm{g} /$ day for budesonide or other ICS equivalents.

(III) It must be noted that if a patient needs to frequently increase the use of bronchodilators (especially SABA) to relieve symptoms, that indicates that asthma is aggravated. More regular evaluation needs to be performed (e.g., Monitoring of daily peak flow with regular follow-up), and the asthma action plan should be updated. The maximum recommended dosage of ICS or oral glucocorticoids should be considered.

\section{Acute exacerbation of chronic obstructive pulmonary disease (AECOPD)}

\section{Assessment and treatment}

Patients are graded according to severity (Table 6) and treatment correspondingly (Figure 5).

\section{Precautions}

(I) The preferred bronchodilator for AECOPD treatment is usually a single SABA inhaler or 
Table 6 Evaluation and grading of AECOPD

\begin{tabular}{lccc}
\hline Variables & $\begin{array}{c}\text { Grade I (no respiratory } \\
\text { failure) }\end{array}$ & $\begin{array}{c}\text { Grade II (non-life-threatening acute } \\
\text { respiratory failure) }\end{array}$ & $\begin{array}{c}\text { Grade III (life-threatening acute } \\
\text { respiratory failure) }\end{array}$ \\
\hline Respiratory rate & 20 to $30 \mathrm{bpm}$ & $>30 \mathrm{bpm}$ & $>30 \mathrm{bpm}$ \\
Assisted respiratory muscle group & Not applied & Applied & Applied \\
Change of cognitive status & No & No & Sudden change \\
\hline
\end{tabular}

AECOPD, acute exacerbation of chronic obstructive pulmonary disease.

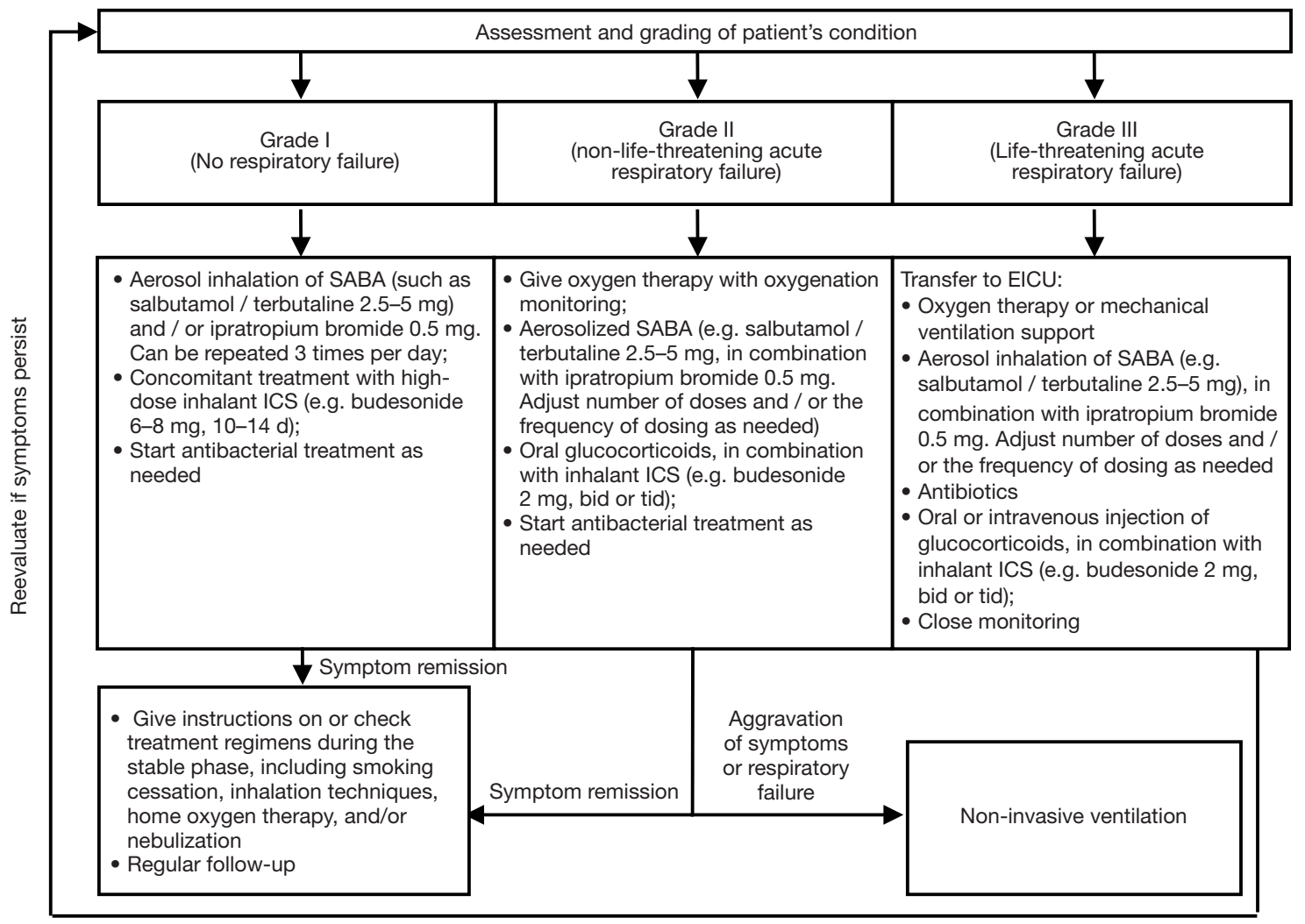

Figure 5 Procedures for the management of AECOPD. AECOPD, acute exacerbation of chronic obstructive pulmonary disease.

concomitantly administered SAMA inhalation.

(II) The use of glucocorticoids can shorten the recovery time, improve lung function and hypoxemia, reduce the risk of early recurrence and treatment failure, and shorten hospital stay. Aerosol inhalation ICS may replace or partially replace systemic glucocorticoids (aerosol inhalation of $8 \mathrm{mg}$ budesonide for AECOPD is equivalent to systemic treatment with $40 \mathrm{mg}$ prednisolone in terms of efficacy).

(III) Increased sputum, thick and sticky sputum, and/or purulent sputum is one of the typical symptoms of AECOPD (28). For AECOPD patients with such symptom and/or at risk of difficulty in coughing up sputum, adding aerosol inhalation of acetylcysteine (0.3 g/time, bid) to conventional treatment is recommended to improve $\mathrm{PaO}_{2}$ and $\mathrm{FEV}_{1}$ as well as relieve clinical symptoms (28).

(IV) Patients at acute exacerbation stage with chronic bronchitis, emphysema, bronchiectasis, pulmonary fibrosis, and pulmonary heart disease often 
Table 7 Evaluation and classification of laryngeal obstruction

\begin{tabular}{lllll}
\hline Variables & $\begin{array}{l}\text { Grade I (no respiratory } \\
\text { failure) }\end{array}$ & Grade II & Grade III & Class IV (life-threatening) \\
\hline Dyspnea & Slight difficulty at rest & Severer than grade I & Appearance of cyanosis & $\begin{array}{l}\text { Severe than grade III, sitting } \\
\text { restlessly }\end{array}$ \\
$\begin{array}{l}\text { Four concave } \\
\text { signs }\end{array}$ & $\begin{array}{l}\text { No wheezing and four } \\
\text { concave signs }\end{array}$ & $\begin{array}{l}\text { Presence of wheezing and } \\
\text { four concave signs at rest }\end{array}$ & $\begin{array}{l}\text { Obvious wheezing and four } \\
\text { concave signs }\end{array}$ & $\begin{array}{l}\text { Severer wheezing and four concave } \\
\text { signs }\end{array}$ \\
$\begin{array}{l}\text { Change in } \\
\text { cognitive status }\end{array}$ & No change & No dysphoria, no obvious & Presence of dysphoria, \\
& change in cognitive status & change in cognitive status & $\begin{array}{l}\text { May experience coma, gatism, } \\
\text { suffocation, and even respiratory } \\
\text { and cardiac arrest in severe cases }\end{array}$ \\
\hline
\end{tabular}

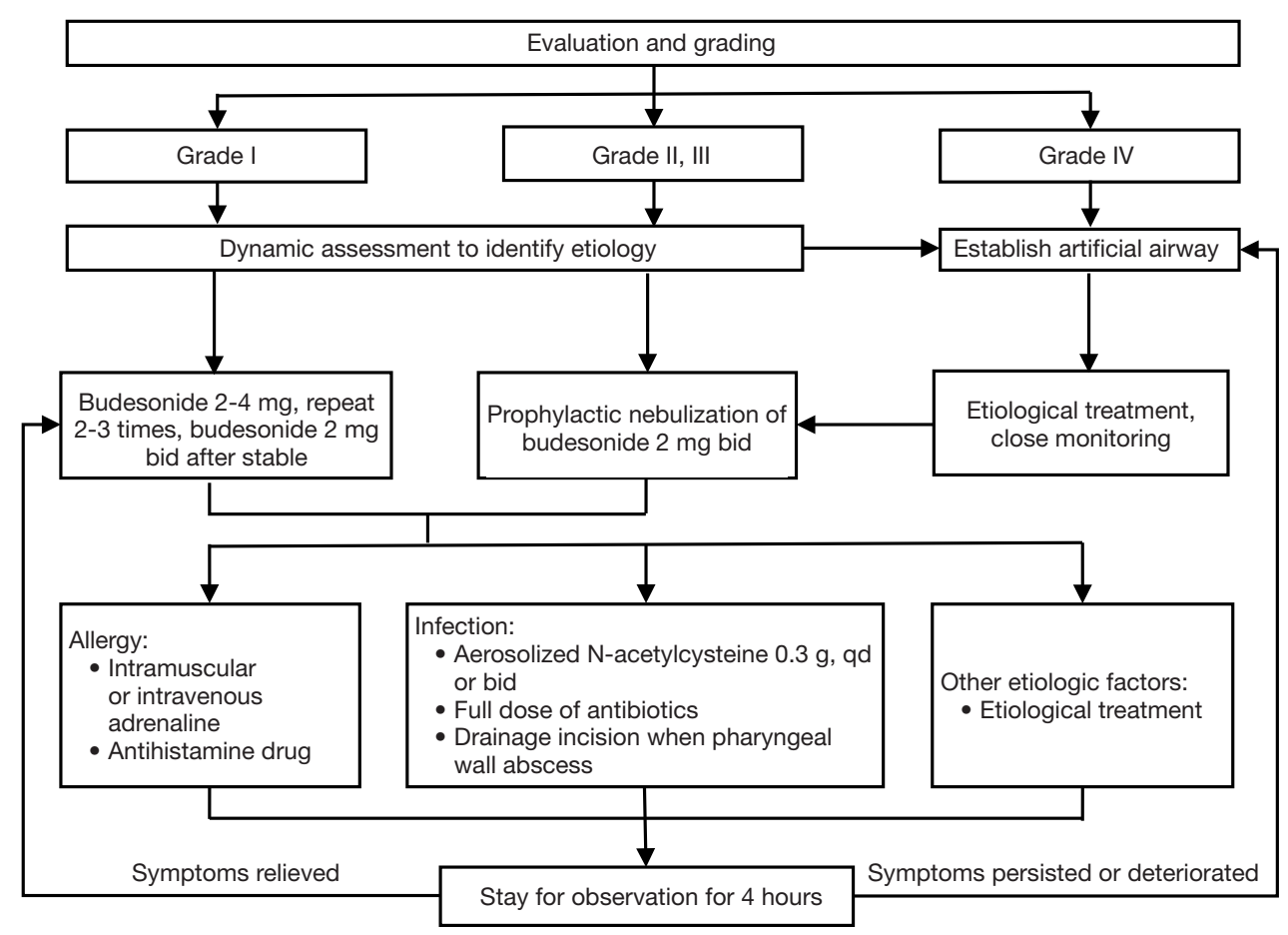

Figure 6 Procedures for the management of acute laryngeal obstruction.

have similar clinical features of AECOPD, with limited airflow, airway hyperactivity, and high secretion. Refer to AECOPD for evaluation and treatment protocol. Aerosol inhalation of ICS, bronchodilator, and $\mathrm{N}$-acetylcysteine can be applied as needed.

\section{Acute laryngeal obstruction}

\section{Assessment and treatment}

Acute laryngeal obstruction (acute epiglottis, acute laryngeal edema, pharyngeal abscess, etc.) tends to aggravate progressively and may progress rapidly over a short period to a life-threatening critical stage. Instant dynamic assessment of the disease severity (Table 7) is required with immediate treatment (Figure 6).

\section{Precautions}

(I) The assessment and treatment for cute laryngeal obstruction must be decisive. For patients who may be or are at a critical stage, an artificial airway should be established as soon as possible. Causes should 
be identified (such as throat inflammation, allergy, infection, trauma, foreign body, tumor, spasm, abduction paralysis of bilateral vocal cords and so on) and etiological therapy should be carried out simultaneously.

(II) Nebulization therapy is one of the emergency measures for inflammation, allergy, and convulsions. The drug can reach throat quickly, relieve the inflammation and edema at the throat, increase the ventilatory capacity, improve the hypoxic state, shorten the time for the symptoms to disappear, and improve the efficiency of rescue (29); it can also be used prophylactically to improve respiratory mucosal damage and local inflammation caused by trauma, artificial airway, as well as to increase respiratory humidity, liquefy viscous secretions, promote the subsidence of mucosal edema, and shorten the hospital stay. No nebulization therapy is required if the foreign body etiology did not cause airway damage or inflammation.

(III) The importance and necessity of adrenaline and antibiotics administration should be highlighted. Although there is no available aerosol formulation, there have been reports that the aerosol inhalation of $1 \mathrm{mg}$ adrenaline leads to blood vessel contraction and improvement of laryngeal edema prognosis (including laryngeal edema following prophylactic intubation) (30).

\section{Acute and subacute cough or chronic cough exacerbation}

Coughing is a defensive nerve reflex for the body. Frequent and severe coughing can have a serious impact on work, life, and social activities. According to its duration, coughing is divided into 3 groups: acute cough ( $<3$ weeks), subacute cough (3-8 weeks) and chronic cough ( $>8$ weeks) (30).

The common etiology of acute cough is common cold and acute tracheal-bronchitis. The common etiology of subacute cough is post-infectious cough (PIC). The most common etiology of chronic cough is hormonesensitive cough, including cough variant asthma (CVA), eosinophilic bronchitis (EB) and atopic cough (AC), accounting for about 2/3 of chronic cough in China (30). Other common etiologic factors include upper airway cough syndrome (UAC) and gastroesophageal refluxrelated cough (GERC), which are often accompanied by postnasal drip sensation and concomitant nasal diseases, or accompanied by obvious reflux symptoms often associated with food intake (31).

In addition to other etiological treatments, for patients with severe cough or wheezing, aerosol inhalation of bronchodilators (e.g., salbutamol/terbutaline $2.5-5 \mathrm{mg}$ bid) in combination with ICS (e.g., budesonide $2 \mathrm{mg}$ bid) is recommended until symptom remission. Diagnostic treatment may be administered (for no less than 2 weeks) using this method for hormone-sensitive cough patients: if the symptom is relieved, the disease is judged to be hormone-sensitive cough. ICS or combined therapy with bronchodilator may be continued; If partial response is achieved, factors affecting treatment efficacy should be evaluated, and the composite etiology should be considered; In case of no response, an assessment is performed to evaluate whether the judgment is wrong, whether the dose and duration of treatment are sufficient, or whether there are factors affecting the efficacy. Other etiologic factors should also be considered. For patients with excess sputum, aerosol inhalation of mucolytic agents may be used, such as $\mathrm{N}$-acetylcysteine $0.3 \mathrm{~g}(3 \mathrm{~mL}) \mathrm{qd}$ or bid for 5 to 10 days. The number of doses and the frequency of dosing may be adjusted according to clinical response and therapeutic effects (32). In patients with airway hyperreactivity, the airway goblet cells are also activated, which often leads to increased mucus secretion. Therefore, for such patients, mucolytic agents may be administered via aerosol inhalation to prevent sputum from blocking the airway.

\section{Pneumonia}

Patients with pneumonia often have increased mucous secretion and sticky and thicken sputum, which leads to retention of sputum and difficulty in pathogens clearance. The aerosol inhalation of $\mathrm{N}$-acetylcysteine $[0.3 \mathrm{~g}(3 \mathrm{~mL})$ once to twice per day] may humidify the airway, facilitate mucus discharge, keep the airway open, enhance the action of anti-infective drugs and accelerate recovery. $\mathrm{N}$-acetylcysteine also impairs the formation of bacterial biofilms. In vitro studies show that $\mathrm{N}$-acetylcysteine interferes with the formation of Pseudomonas aeruginosa biofilm and destroy formed biofilm in a concentrationdependent manner (33).

Pathogen stimulation can also cause airway spasm, 
mucosal edema, and inflammatory exudation. If the patient shows symptoms such as shortness of breath, wheezing, dyspnea or coughing, the combined aerosol inhalation with bronchodilators (such as salbutamol/terbutaline $5 \mathrm{mg}$ bid) and ICS (such as budesonide $2 \mathrm{mg}$, bid) may be considered to quickly relieve bronchospasm, reduce airway inflammation and mucosal edema, and promote airway epithelial repair and pneumonia healing (34). ICS can also be administered in combination with the mucolytic agent in nebulization therapy. Studies have shown that $\mathrm{N}$-acetylcysteine in combination with budesonide inhalation is superior to budesonide alone for the treatment of bronchial pneumonia in terms of time for improvement of clinical symptoms as well as overall response rate (35).

Also, for patients with no mucus production, aerosol inhalation of hypertonic saline may be administered when collecting phlegm sample. Aerosol inhalation of non-nebulized antibacterial agents is not recommended. However, for critical patients with no response to intravenous antibiotics, which need strict control of fluid intake and have multidrug-resistant bacteria (MDR) infection, combined treatment with aerosol inhalation antibiotics may be considered.

\section{Acute respiratory distress syndrome (ARDS)}

ARDS is an acute and diffuse inflammatory lung injury (36), whose pathophysiological basis is the systemic inflammatory response syndrome. Glucocorticoids can inhibit inflammatory response at multiple levels, reducing pulmonary capillary permeability and alveolar membrane damage and improving tissue tolerance to hypoxia $(37,38) ; \beta 2$ receptor agonists can activate $\mathrm{AC}$ and increase cAMP by acting on alveolar type II epithelial cells, thereby stabilizing the release of cellular lysosomal enzymes and reducing cellular damage (39). It is recommended in 2016 Japan ARDS Management Guide that adult patients be treated with glucocorticoids at a dose equivalent to methylprednisolone $1-2 \mathrm{mg} / \mathrm{kg} / \mathrm{d}$ (grade 2B level of evidence) (40). Studies have shown that, during the pulmonary protective mechanical ventilation for ARDS patients, aerosolized budesonide ( $1 \mathrm{mg}$ per time, bid) can significantly improve oxygenation index and reduce airway pressure and inflammation levels (41). Aerosolized salbutamol/terbutaline $(2.5-5 \mathrm{mg}$, bid) can be concomitantly used.

\section{Burn patients: smoke inbalation-associated acute lung injury (SI-ALI)}

SI-ALI is the common cause of death in fire-burn patients. The causative factors for SI-ALI include chemical factors and thermal factors. Since the upper respiratory tract absorbs most of the heat before the smoke reaches the tracheal carina, chemical factors are the primary cause of inhalation-associated lung injury. Smoke can directly act on lung tissues and cause direct lung damages. It can also cause indirect lung damage by activating neutrophils, macrophages, and platelets. After inhalation of smoke, bronchial blood flow is significantly increased. Blood can enter the pulmonary blood vessels through the bronchial-pulmonary vascular anastomosis, resulting in pulmonary edema (42). Also, the activated neutrophils, endothelial cells, macrophages, and vascular smooth muscle cells release massive cytokines, inducing the massive production of iNOS, eventually damaging the alveolar-capillary membrane, increasing pulmonary vascular permeability, reducing pulmonary vascular diffusion ability, resulting in pulmonary edema $(43,44)$. Particles in the smoke fill the airway and are difficult to be removed by the body. Viscous airway secretions can also cause extensive airway obstruction. Also, smoke inhalation may cause increased vascular resistance and neutrophil aggregation and activation, leading to damage to the pulmonary capillaries and alveoli $(42,45)$. Glucocorticoids can inhibit inflammatory responses from various causes through multiple signaling pathways (46). $\beta 2$ receptor agonists may dilate bronchi, reduce airflow resistance, and increase dynamic compliance of lungs (47). Anticoagulants can block the formation of fibrin clots. Tissue plasminogen activator dissolves fibrinogen and fibrin. Together they play an important role in the treatment of SI-ALI.

\section{Other diseases or population using nebulization therapy}

Other indications for nebulization therapy include: (I) nonspecific inflammatory diseases such as allergic rhinitis, throat inflammation, and edema. (II) Patients with carbon monoxide poisoning, irritating gas poisoning and so on have airway mucosal damage, edema and inflammation, often accompanied by cough, expectoration, wheezing, and other symptoms. The recommended therapy is aerosolized ICS 
in combination with a bronchodilator (such as budesonide $2 \mathrm{mg}+$ salbutamol/terbutaline $5 \mathrm{mg}$, bid); If necessary, $\mathrm{N}$-acetylcysteine may be used in combination because it can effectively reduce laryngeal edema and airway obstruction and improve related symptoms and prognosis (48). (III) Patients who are long-term bedridden or judged to be long-term bedridden and at risk of hypostatic pneumonia, including traumatic brain injury (49), chest injury (rib fracture or lung contusion, blood pneumothorax), fracture and so on, as well as tumor, stroke and other medical diseases, are prone to limited mucus-discharging ability, decreased inherent cough reflex, mistaken aspiration, obstructed discharge of phlegm, airway obstruction, mucosal edema, inflammation and infection due to limited mobility with underlying reduced respiratory function and cognitive disorder. The prophylactic use of $\mathrm{N}$-acetylcysteine (0.3 g, QD to bid, for 7 days) is recommended (50). Meanwhile help the patients to turn over and pat on the back to promote sputum excretion, in order to effectively prevent the occurrence of hypostatic pneumonia. (IV) Patients with underlying respiratory conditions or airway hyperactivity at high risk of inflammation can receive the concomitant therapy with aerosolized ICS, bronchodilator, and $\mathrm{N}$-acetylcysteine to help reduce mucus secretion and mucosal edema, protect epithelial barrier function, prevent infection and improve prognosis. (V) Perioperative airway management. Perioperative nebulization can improve the symptoms of bronchial obstruction, protect throat mucosa and airway epithelium, reduce post-extubation airway damage, improve postoperative airway inflammation and decrease pulmonary surfactant and the incidence of pulmonary complications (11). Preoperative prophylactic aerosol inhalation with $\mathrm{N}$-acetylcysteine ( $0.3 \mathrm{~g}$ qd or bid) is recommended until the patient is recovered and discharged. Also, for patients with airway hyperactivity and high-risk factors for pulmonary function decline (such as old age, obesity, smoking history and underlying diseases), the recommended management is the aerosolized budesonide $2 \mathrm{mg}$ bid or tid from one week before operation till three months after operation (11). (VI) For patients receiving laryngoscopy and bronchoscopy, aerosol inhalation can reduce airway damage and lower airway hyperactivity. (VII) Special Populations. Due to a good safety profile, nebulization therapy is advantageous in children, pregnant women, and patients with underlying diseases such as concomitant vascular disease, diabetes, and osteoporosis.
The inhalation therapy of ICS can serve as a substitution for intravenous or oral corticosteroids, with the advantages of rapid onset and good safety profile.

\section{Special application in EICU, mechanical ventilation, artificial airway establishment, and surgery}

In emergency and first aid treatment, patients who are admitted into EICU and need procedures such as mechanical ventilation, artificial airway establishment, and surgery are often seriously ill with concomitant respiratory failure and physiological and metabolic disorders. Effective application of aerosol inhalation can reduce the ventilation-caused adverse reactions such as respiratory mucosa dryness and injury (51). Also, etiological treatment drug can be concomitantly administered to facilitate rapid recovery and improve the weaning efficiency from mechanical ventilator (52).

Since aerosol inhalation in mechanical ventilation is less efficient than that in autonomous inhalation, the dosage, frequency, and duration of treatment should be increased accordingly. For example, for salbutamol/terbutaline 5-10 mg, budesonide $2-4 \mathrm{mg}$, bid, the treatment should last for at least 3 days until weaning from mechanical ventilation (41). Evidence suggests that, based on the etiological therapeutic dose, during the interval of mechanical ventilation, it is more beneficial if extra doses of aerosolized ICS (budesonide $0.5 \mathrm{mg}$ bid) are inhaled by spontaneous breathing (53).

In patients with established artificial airway, procedures such as tracheal intubation and extubation often cause mechanical irritation or damage to the airway, resulting in airway hyperactivity and inflammatory changes. Studies have shown that administration of ICS 12-24 hours before extubation can reduce post-extubation airway damage and incidence of airway inflammation (such as laryngeal edema and wheezing.) and pulmonary complications after extubation $(54,55)$. Similar to patients receiving mechanical ventilation, the dose, times, and maintenance duration (days) should be appropriately increased during the establishment of the artificial airway. Based on the etiological therapeutic dose, $1 \mathrm{mg}$ of budesonide is inhaled 1 hour before the recommended extubation, and $1 \mathrm{mg}$ of budesonide is inhaled after extubation, bid for 2 days (56).

The application of nebulization therapy in the emergency treatment of the diseases mentioned above is summarized in (Figure 7). 

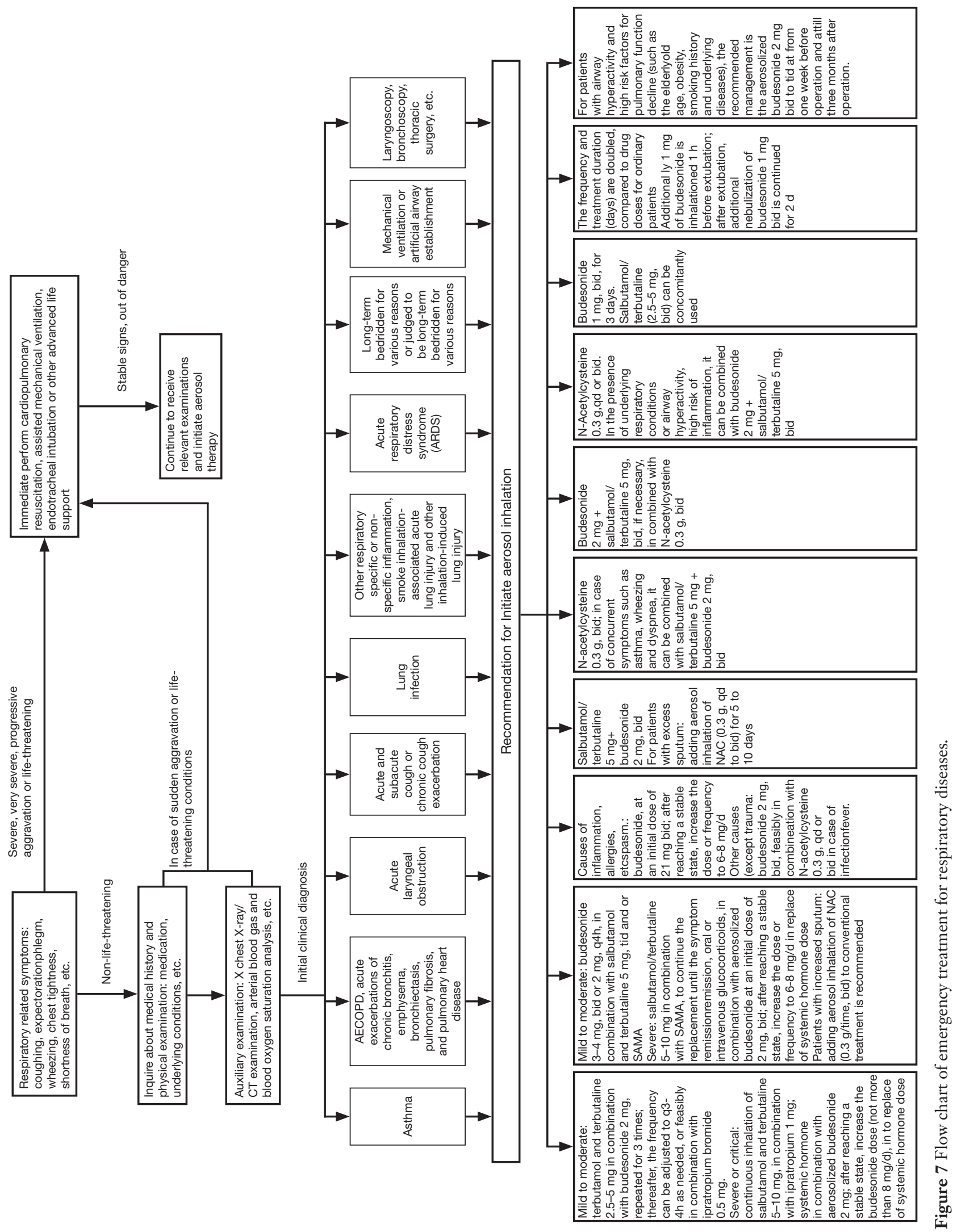


\section{Acknowledgments}

None.

\section{Footnotes}

Conflicts of Interest: The authors have no conflicts of interest to declare.

Ethical Statement: The authors are accountable for all aspects of the work in ensuring that questions related to the accuracy or integrity of any part of the work are appropriately investigated and resolved.

\section{References}

1. Yu QL, Zhu SJ, Liang AP, et al. Investigation into the classification of diseases contracted by 82598 emergency cases. Chinese Journal of Hospital Administration 2001;17:599-601.

2. Hao L, Yin W, Huang Y, et al. Emergency Disease Sectrum Analysis: Report of 55650 Cases. Chinese General Practice 2008;11:1070-2.

3. Tao HM, Leng QY, Wang CW. The epidemiological characteristics and disease spectrum composition of 18613 patients from emergency department. Journal of Trauma and Emergency (Electronic Version) 2013;1:32-6.

4. Huang S, Man D, Ba T, Mu Q. Distribution and epidemiological characteristics of disease spectrum in patients with pre-hospital care in Hohhot in 2016: a case analysis in 28325 patients. Zhonghua Wei Zhong Bing Ji Jiu Yi Xue 2018;30:78-82.

5. Chen XJ, Deng XG, Qiu SH, et al. Analysis of disease categories, occurrence and distribution of pre-hospital care in emergency center. China Medicine 2017;12:264.

6. Zhang ZQ, Chen WB, Chen WY, et al. The epidemiological characteristic of 97823 cases of prehospital medical care in Guangzhou city. Chinese Critical Care Medicine 2011;23:99-103.

7. Ibrahim M, Verma R, Garcia-Contreras L. Inhalation drug delivery devices: technology update. Med Devices (Auckl) 2015;8:131-9.

8. Expert Group of Expert Consensus on Nebulization Therapy in Respiratory Diseases C T S. Expert consensus on nebulization therapy in respiratory diseases. National Medical Journal of China 2016;96:2696.

9. Zhu Z, Zheng J, Wu Z, et al. Clinical practice of nebulized therapy in China: a national questionnaire survey. $\mathrm{J}$
Aerosol Med Pulm Drug Deliv 2014;27:386-91.

10. Chen AH, Zeng GQ, Chen RC, et al. Effects of nebulized high-dose budesonide on moderate-to-severe acute exacerbation of asthma in children: a randomized, doubleblind, placebo-controlled study. Respirology 2013;18 Suppl 3: 47-52.

11. Zhi XY, He JX, Liu LX, et al. Chinese Expert Consensus Statement on Multi-disciplinary Perioperative Airway Management (2016 Version). Chinese Journal of Clinical Thoracic and Cardiovascular Surgery 2016;3:641-5.

12. Sun X, He Z, Zhang J, et al. Compare the efficacy of inhaled budesonide and systemic methylprednisolone on systemic inflammation of AECOPD. Pulm Pharmacol Ther 2015;31:111-6.

13. Brattsand R, Miller-Larsson A. The role of intracellular esterification in budesonide once-daily dosing and airway selectivity. Clin Ther 2003;25:C28-41.

14. Zhou J, Liu DF, Liu C, et al. Glucocorticoids inhibit degranulation of mast cells in allergic asthma via nongenomic mechanism. Allergy 2008;63:1177-85.

15. Mendes ES, Rebolledo P, Campos M, et al. Immediate antiinflammatory effects of inhaled budesonide in patients with asthma. Ann Am Thorac Soc 2014;11:706-11.

16. Tsai YG, Lee MY, Yang KD, et al. A single dose of nebulized budesonide decreases exhaled nitric oxide in children with acute asthma. J Pediatr 2001;139:433-7.

17. Expert Group of Expert Consensus on Nebulization Therapy of Adult Chronic Respiratory Diseases. Expert consensus on nebulization therapy of adult chronic respiratory diseases. Chinese Journal of Respiratory and Critical Care Medicine 2012;11:105-10.

18. Aldini G, Altomare A, Baron G, et al. N-Acetylcysteine as an antioxidant and disulphide breaking agent: the reasons why. Free Radic Res 2018;52:751-62.

19. Sadowska AM. N-Acetylcysteine mucolysis in the management of chronic obstructive pulmonary disease. Ther Adv Respir Dis 2012;6:127-35.

20. Santus P, Corsico A, Solidoro P, et al. Oxidative stress and respiratory system: pharmacological and clinical reappraisal of $\mathrm{N}$-acetylcysteine. COPD 2014;11:705-17.

21. Blasi F, Page C, Rossolini GM, et al. The effect of $\mathrm{N}$-acetylcysteine on biofilms: Implications for the treatment of respiratory tract infections. Respir Med 2016;117:190-7.

22. Chinese College of Emergency Physicians, Committee of PLA, Beijing Society for Emergency Medicine, et al. Expert consensus on nebulization therapy in emergency care (2018). Chinese Journal of Critical Care Medicine 
2018; 38:565-74.

23. Labiris NR, Dolovich MB. Pulmonary drug delivery. Part I: Physiological factors affecting therapeutic effectiveness of aerosolized medications. Br J Clin Pharmacol 2003;56:588-99.

24. Sheth P, Stein SW, Myrdal PB. The influence of initial atomized droplet size on residual particle size from pressurized metered dose inhalers. Int J Pharm 2013;455:57-65.

25. Vaghi A, Berg E, Liljedahl S, et al. In vitro comparison of nebulised budesonide (Pulmicort Respules) and beclomethasone dipropionate (Clenil per Aerosol). Pulm Pharmacol Ther 2005;18:151-3.

26. Martin AR, Finlay WH. Nebulizers for drug delivery to the lungs. Expert Opin Drug Deliv 2015;12:889-900.

27. Asthma Group of Chinese Thoracic Society; China Asthma Alliance. The Chinese experts' consensus on the evaluation and management of asthma exacerbation. Zhonghua Nei Ke Za Zhi 2018;57:4-14.

28. Wang HM, Tang D, Li G. Clinical observation on $\mathrm{N}$-Acetylcysteine inhalation in treatment of elderly patients with AECOPD. Journal of Clinical Pulmonary Medicine 2017;22:1437-9.

29. Liu HY, Qiu L. Emergency care for acute laryngeal obstruction. Guide of China Medicine 2016;14:271-2.

30. Asthma Group of Chinese Thoracic Society. Guideline on diagnosis and treatment of cough (2015). Chinese Journal of Tuberculosis and Respiratory Diseases 2016;39:323.

31. Lai KF, Liu BJ. Clinical characteristics and treatment of corticosteroids responsive cough. Chinese Journal for Clinicians 2014;42:8-10.

32. FLUMUCIL®: Acetylcysteine Solution for Inhalation Package Insert. 2012.

33. Zhao T, Liu Y. N-acetylcysteine inhibit biofilms produced by Pseudomonas aeruginosa. BMC Microbiol 2010;10:140.

34. Chinese College of Emergency Physicians. Expert consensus on management of adult community-acquired pneumonia (Part one). Chinese Journal of Critical Care Medicine 2011;31:961-7.

35. Song HL. Efficacy of N-acetylcysteine Combined with Budesonide in the Treatment of Bronchial Pneumonia in Childen through Aerosol Inhalation. Chinese and Foreign Medical Research 2017;15:20-2.

36. Respiratory and Critical Care Medicine Group of Chinese Thoracic Society. Guideline on mechanical ventilation of acute respiratory distress syndrome patients(Draft). National Medical Journal of China 2016;96:5.

37. Cui DJ. Updates on pathogenesis and treatment of acute respiratory distress syndrome. Chinese Journal of Practical Surgery 2002;22:701-4.

38. Artigas $\mathrm{A}$, Camprubí-Rimblas $\mathrm{M}$, Tantinyà $\mathrm{N}$, et al. Inhalation therapies in acute respiratory distress syndrome. Ann Transl Med 2017;5:293.

39. He L, Li TP, Zhu LH. Alveolar fluid clearance and changes of alveolar type II cell cAMP and cGMP levels in rats with oleic acid-induced acute respiratory distress syndrome. Nan Fang Yi Ke Da Xue Xue Bao 2008;28:513-6.

40. Hashimoto S, Sanui M, Egi M, et al. The clinical practice guideline for the management of ARDS in Japan. J Intensive Care 2017;5:1-32.

41. Mohamed HS, Meguid MM. Effect of nebulized budesonide on respiratory mechanics and oxygenation in acute lung injury/acute respiratory distress syndrome: Randomized controlled study. Saudi J Anaesth 2017;11:9-14.

42. Sun L, Li DB, Cao J. Advances in the pharmacotherapy of acute lung injury induced by smoke inhalation. International Journal of Respiration 2011;31:56-61.

43. Hasnis E, Burbea Z, Reznick AZ. Mechanisms Underlying Cigarette Smoke-Induced Nf- $\kappa \mathrm{B}$ Activation in Human Lymphocytes. 2009:1-16.

44. Lee AS, Mellins RB. Lung injury from smoke inhalation. Paediatr Respir Rev 2006;7:123-8.

45. Demling RH. Smoke inhalation lung injury: an update. Eplasty 2008;8:e27.

46. van der Velden VH. Glucocorticoids: mechanisms of action and anti-inflammatory. Mediators Inflamm 1998;237:229-37.

47. Miller AC, Elamin EM, Suffredini AF. Inhaled anticoagulation regimens for the treatment of smoke inhalation-associated acute lung injury: a systematic review. Crit Care Med 2014;42:413-9.

48. Editorial Group of Management of Airway Mucus Hypersecretion in Chronic Airway Inflammatory Disease: Chinese Expert Consensus. Management of airway mucus hypersecretion in chronic airway inflammatory disease: Chinese expert consensus. Chinese Journal of Tuberculosis and Respiratory Diseases 2015;38:723-9.

49. Stang A. Critical evaluation of the Newcastle-Ottawa scale for the assessment of the quality of nonrandomized studies in meta-analyses. Eur J Epidemiol 2010;25:603-5.

50. Elamin E, Miller A. Impact of nebulized unfractionated heparin and $\mathrm{N}$-acetylcysteine in management of smoke inhalation injury. Critical Care 2009;13:P438.

51. Dolovich MB, Ahrens RC, Hess DR, et al. Device selection and outcomes of aerosol therapy: Evidence- 
based guidelines: American College of Chest Physicians/ American College of Asthma, Allergy, and Immunology. Chest 2005;127:335-71.

52. Hashemian SM, Mortaz E, Jamaati H, et al. Budesonide facilitates weaning from mechanical ventilation in difficult-to-wean very severe COPD patients: Association with inflammatory mediators and cells. J Crit Care 2018;44:161-7.

53. Davidson AC, Banham S, Elliott M, et al. BTS/ICS guideline for the ventilatory management of acute hypercapnic respiratory failure in adults. Thorax 2016;71 Suppl 2:ii1-35.

54. Khemani RG, Randolph A, Markovitz B. Corticosteroids

Cite this article as: Chinese College of Emergency Physicians (CCEP), Emergency Committee of PLA, Beijing Society for Emergency Medicine, Chinese Emergency Medicine. Expert consensus on nebulization therapy in pre-hospital and inhospital emergency care. Ann Transl Med 2019;7(18):487. doi: 10.21037/atm.2019.09.44 for the prevention and treatment of post-extubation stridor in neonates, children and adults. Cochrane Database Syst Rev 2009;(3):CD001000.

55. François B, Bellissant E, Gissot V, et al. 12-h pretreatment with methylprednisolone versus placebo for prevention of postextubation laryngeal oedema: a randomised doubleblind trial. Lancet 2007;369:1083-9.

56. Kashefi P, Abbasi A, Abbasi M, et al. Comparison of the efficacy of nebulized budesonide and intravenous dexamethasone administration before extubation in prevention of post-extubation complications among patients admitted in intensive care unit. Adv Biomed Res 2015;4:11. 
Supplementary

Table S1 Parameters for nebulization efficiency of some clinically used nebulizers

\begin{tabular}{lcccc}
\hline Nebulizer & Nebulizer type & Diameter of aerosol & The volume of drug solution & Output rate \\
\hline Omron NE-C28 & Jet nebulizer & Less than $5 \mu \mathrm{m}$ & About 2-7 mL & About $0.4 \mathrm{~mL} / \mathrm{min}$ \\
Omron NE-C900 & Jet nebulizer & $3-5 \mu \mathrm{m}$ & About 2-7 $\mathrm{mL}$ & About $0.4 \mathrm{~mL} / \mathrm{min}$ \\
$\begin{array}{l}\text { Philips medical ultrasonic } \\
\text { nebulizer }\end{array}$ & Ultrasonic nebulizer & $4.07 \pm 0.6 \mu \mathrm{m}$ & Maximum storage capacity up to $8 \mathrm{~mL}$ & $0.55 \mathrm{~mL} / \mathrm{min}$ \\
Homed 2311HD & Jet nebulizer & $0.5-6 \mu \mathrm{m}$ & $8 \mathrm{~mL}$ & $>0.25 \mathrm{~mL} / \mathrm{min}$ \\
\hline
\end{tabular}


Budesonide Treat bronchial asthma, rapidly reduce inflammation, relieve a rapidly reduce inflammation, relieve airway mucosal lung function systemic hormones, at a dose of no more than $8 \mathrm{mg}$ per

Beclomethasone It can treat asthma and improve bronch obstruction. With the anti-inflammatory, anti-allergic and anti-itching effects, it can inhibit bronchial exudate, eliminate bronchial mucosal swelling, and reliev bronchospasm

Fluticasone Moderate acute asthma attack in child

propionate and adolescents aged 4-16 years for an acute asthma attack. Use for no more than 7 days,

Bronchodilatation drug

Salbutamol Relief of bronchospasm from asthma or as the acute prive induced asthma, or allergen-induced bronchospasm
Terbutaline With the rapid onset of action for relief of bronchospasm. Has less impact on heart rate, making it particularly suitab for patients with coronary heart disease tachycardia, and other cardiovascular diseases

Ipratropium Improve lung function and improve arteria bromide oxygen saturation.

Mucolytic agent

$\mathrm{N}$-acetylcysteine Reduce the viscosity of the sputum making the mucus clearance easy fitme, bid. The maximum initial dose is recommended
Acute asthma attack: 1-2 mg intermittently (every 20 minutes) or continuous nebulization over the first hour, followed by day. AECOPD: it can replace or partially replace systemic hormones for no more than $8 \mathrm{mg}$ per day. Others: the conventional dose is $1-2 \mathrm{mg}$ bid, dose and dosing frequency can be adjusted according to the specific situation Adult: packaged in a single-dose vial, administered via a per time, once to twice per day. Adult: half dose of the single-dose vial, administered via a nebulze 0.5 vials per time, once to twice per day. The half dose is marked with a graduation on the single dose vial. Shake we before use injection immediately before administration to prolong the duration of drug inhalation. It is recommended to use mouthpiece inhaler and a non-ultrasonic nebulizer

It is contraindicated in patients who are allergic to budesonide or any other ingredient

Patients with the local virus and cognitive disorder culosis infection during active or stationary phase.

Patients are allergic to any component of this

product. The use of pregnant women and lactating

women is forbidden

is contraindicated in patients who are allergic to any of the ingredients in the drug product

Contraindicated in patients with premonitory abortion and those who are allergic to any symptom improvement. AECOPD: $2.5-5 \mathrm{mg}$ bid, dose, conditions. Others: the conventional dose is $2.5-5 \mathrm{mg}$ bid dose and dosing frequency can be adjusted according to the specific situation
Mild throat irritation, pyrexia, sinusitis, pain, pharyngitis, bronchospasm, bronchitis, and headache

Candidiasis, hoarseness, and throat irritation in the mouth and throat

Tremors, headache, tachycardia, palpitation, irritation of the mouth and throat, muscle spasms. Cautions for patients taking high-dose sympathomimetic drugs concomitantly. Cautions in patients with thyrotoxicosis. Non-isotonic or non--neus solutions or benzalkonium chloride-containing solutions can cause paradoxical

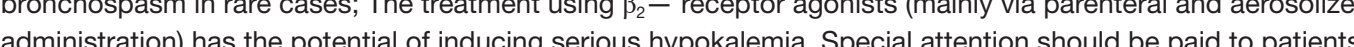
with serious acute asthma because the concomitant administration of xanthine derivatives and corticosteroids, diuretics, and hypoxia will increase the occurrence of hypokalemia. It is suggested that the blood potassium leve is monitored for the conditions mentioned above. Salbutamol can cause reversible metabolic changes, such as elevated levels of blood glucose. The concomitant use of corticosteroids can aggravate these effects. A few cases of angle-closure glaucoma when concomitantly receiving aerosolized salbutamol and ipratropium bromide. Caution should be exercised when concomitantly use aerosolized anticholinergic drugs and aerosolized salbutamol. Lactic acidosis associated with high-dose shot -acting p-agonists for intravenous and nebulzaton therapy are rare and are found primarily in asthma patients with acute aggravation undergoing treatment. On-site monitor for elevated serum lactate leves and the ponconlant metabolic acidosis is recommended. Caution for Athletes

Acute asthma attack: $5 \mathrm{mg}$ intermittently (every 20 minutes) or It is contraindicated in patients allergic to terbutaline Headache, palpitation, tachycardia, tremors, muscle spasm 5-10 mg continuous nebulization until symptom improvement. sulfate or any of the ingredients in the drug product AECOPD: $5 \mathrm{mg}$ bid, dose, or trequency can be increased

per day

Regular dose $0.5 \mathrm{mg} /$ time, single dose vial, $3-4$ times per day; Contraindicated in patients allergic to atropine and medical supervision for daily dose over $2 \mathrm{mg} \quad$ product

Headache, dizziness, anxiety, tachycardia, skeletal muscle fine tremor, palpitation, potential severe hypokalem nausea, vomiting, sweating, muscle weakness, myalgia, muscle cramp. Severe anticholinergic side effects method of topical administration. Mild systemic anticholinergic effects include dry mouth, the disorder in visua accommodation, and tachycardia

The conventional dose is $0.3 \mathrm{~g}$ per time, once to twice $\mathrm{per}$ day. Dose and frequency of dosing can be adjusted according
to the clinical response and treatment effect 